\title{
PROJETO ARQUITETÔNICO PARA RELOCAÇÃO DA NOVA BIBLIOTECA PÚBLICA MUNICIPAL E PARQUE DE LEITURA - CIDADE DE PRESIDENTE PUDENTE/SP.
}

\author{
Patrícia Portioli Mathias Teixeira, Korina Aparecida Teixeira Ferreira Da Costa \\ Universidade do Oeste Paulista - UNOESTE, Curso de Arquitetura e Urbanismo, Presidente Prudente, SP. E-mail: \\ patriciaportiolli@hotmail.com
}

\section{RESUMO}

O projeto da nova biblioteca municipal vem com intuito de criar um espaço que seja convidativo para as pessoas entrar, usar e permanecer fazendo a integração do público com o lugar e promovendo a aproximação com o hábito da leitura, atraindo o público através de pontos de encontros e lazer que permite sua permanência. $O$ projeto traz também um breve resgate à memória da antiga ocupação do edifício que era o cinema Cine João Gomes muito conhecido na cidade de Presidente Prudente. Com a grande circulação de pedestres foram propostos ambientes que começam na parte externa com uma praça e parklets abertos, e com a transparência do edifício torna visível o interior atraindo o público para dentro da biblioteca, além de proporcionar iluminação e ventilação natural para maior conforto visual e térmico no interior do edifício, com espaços acessíveis para pessoas portadoras de deficiência.

Palavras-chave: Biblioteca Publica; Leitura; Integração; Lazer; Atrativa.

\section{ARCHITECTURAL PROJECT FOR RELOCATION OF THE NEW MUNICIPAL PUBLIC LIBRARY AND READING PARK - CITY OF PRESIDENT PUDENTE / SP.}

\begin{abstract}
The project of the new municipal library comes with the intention of creating a space that is inviting for people to enter, use and stay doing the integration of the public with the place and promoting the approximation with the habit of reading, attracting the public through meeting points and leisure that allows you to stay. The project also brings a brief rescue to the memory of the former occupation of the building that was Cine Cine Gomes very well known in the city of Presidente Prudente. With the great circulation of pedestrians were proposed environments that start in the outside with a square and open parklets, and with the transparency of the building makes visible the interior attracting the public into the library, in addition to providing natural lighting and ventilation for greater visual comfort and thermal room inside the building, with spaces accessible for people with disabilities.
\end{abstract}

Keywords: Public Library; Reading; Integration; Recreation; Attractive. 


\section{INTRODUÇÃO}

No Sudeste do Brasil, no Estado de São Paulo, na região Oeste do Estado, esta localizada o município de Presidente Prudente, foi fundado em 1917, e passou a ser uma cidade atraída pela população através de uma linha férrea, que teve grande importância para o desenvolvimento e crescimento do municio e região. As terras férteis da região trouxe a produção cafeeira, que era uma boa opção de trabalho e renda para os colonizadores, provida de mão de obra para agricultura, tornando a colonização muito mais rápida e fácil. Portanto teve uma expansão urbana, com a exportação produção e importando a produção de café, e aumento ainda o centro comercial para recepção das mercadorias e prestação de serviços. (PORTAL PRUDENTE, 2017).

A primeira biblioteca Municipal da cidade de Presidente Prudente foi criada em 1944, que tem como nome Dr. Abelardo de Cerqueira Cesar, que foi o relator do projeto, com doações de acervo da Academia Dr. Joaquim Murtinho, contando com mais de 70 mil livros, além de jornais, revistas e fitas VHS. (MISAEL, 2014).

Com o passar do tempo, o núcleo urbano prudentino cada vez mais crescia no centro comercial, industrial e de serviços. Percebe-se que desde a fundação do primeiro colégio são grandes os números de alunos que são filhos de profissionais e comerciantes, e de menor numero os de funcionários públicos. (DE PAULA, 2016).

Era no centro prudentino que ocorria os encontros sociais, que era atraídos através dos espaços públicos e privados, o maior fluxo do local central se dava pelo comercio, e lugares sociais aos tempos livres. Os lugares que mais se destacavam era a pista de dança e panificadora, os cinemas muito frequentados pelos jovens, se destacou pelo grande desenvolvimento sociocultural da cidade. (DE PAULA, 2016).

O Cinema Cine João Gomes, se localizava no coração da cidade, e o ponto principal da área central, ficava em frente à praça onde acontecia os chamados "footing" que significava um passeio noturno, onde as jovens caminhavam pelas ruas enquanto os homens as observavam. Nesse sentido o cinema ficou como um marco histórico para o município de Presidente Prudente. (DE PAULA, 2016).

O calçadão é o lugar de maior circulação de pessoas da cidade, mas após o encerramento do horário comercial ocorre um esvaziamento inesperado, e assim tornando propicio para atividades ilegais como marginalização, prostituição, vandalismo, fazendo que a maior parte da população não frequente o lugar. (SCHWAMBACH; ASSAD; LANZETTA,2012).

Várias pessoas idosas, que frequentavam antes aquele local ainda continuam indo diariamente ao centro durante o dia. Caracterizado antes como um lugar de muito lazer e recepção de viajantes, hoje em dia recebe população da região toda em seu comercio, não foram mudanças boas ou ruins, mas sim resultados que ajudaram para o crescimento da cidade. (SCHWAMBACH; ASSAD; LANZETTA, 2012).

\section{METODOLOGIA}

Com presente trabalho de pesquisa qualitativa, foram realizados levantamentos de alguns antecedentes que serve de referencia para o tema proposto, e seus aspectos positivos que irão contribuir para a elaboração das diretrizes projetais.

Em seguida foram realizadas pesquisas do histórico da Cidade de Presidente Prudente, e breve das bibliotecas já existentes em especial a Municipal, com alguns levantamentos. Logo também foram feitos levantamentos do local previsto, com analise do entorno de um raio de $200 \mathrm{~m}$ até o mais próximo de $100 \mathrm{~m}$, com informações de ventilação, insolação, topografia, entorno, etc.

O objeto de estudo está localizado no Estado de São Paulo, em Presidente Prudente, no bairro Uep1-s.1, que fica no coração da cidade, na área central. É um lote de aproximadamente $2600 \mathrm{~m}^{2}$, a área possui dois empreendimentos, um é a Caixa Econômica, que da acesso pela Av. 
Cel. José Soares Marcondes, e o outro é a loja Chick Center Modas que tem acesso pela Rua Tem. Nicolal Maffei, além de ter uma lacuna presente ao lado.

\section{RESULTADOS}

A biblioteca municipal de Presidente Prudente está localizada no Centro Cultural Matarazo desde 2009, que abriga diversas outras atividades que estejam ligadas a cultura como o teatro, escola de música, sala de cinema, auditório, sala de exposição, ateliê, etc. Tem um valor histórico, pois era uma indústria tombada como matrimonio desde o ano de 1980. (PRESIDENTE PRUDENTE, 2014).

A biblioteca abre de segunda a sexta-feira das $8 \mathrm{~h} 30$ às $19 \mathrm{~h}$ e aos sábados das $8 \mathrm{~h} 30$ às $12 \mathrm{~h} 30$, e também tem atendimento através de agendamento, que é para grandes grupos escolares ou visitantes. (PRESIDENTE PRUDENTE, 2014).

No setor que esta implantada a biblioteca, possuem várias outras atividades ao seu redor, mas a área usada pela biblioteca é aproximadamente $760 \mathrm{~m}^{2}$ (SOUZA SOBRINHO, 2017). O edifício passa despercebido pelo público, que não sabe de sua existência e sem indicar se quer uma sinalização de funcionamento. Está localizado em um acervo que dá acesso por um bulevar dentro do Centro Cultural Matarazo.

Os locais acessíveis são, a rampa de acesso, corrimão nas escadas e rampas, estacionamento exclusivo para idosos e deficientes, banheiros e bebedouro adaptados. (JUSTEL, 2018). Os ambientes se organizam em circulação publica que tem recepção na entrada da biblioteca, segue para o acervo aberto onde se pode circular livremente pelo acervo e escolher o livro de interesse, logo esse ambiente se dá para outros dois ambientes público que é o infocentro e a seção de periódicos. (SOUZA SOBRINHO, 2017).

Assim se dá para circulação privada, que são áreas que só pode entrar pessoas autorizadas e funcionários, o acesso para o setor privado é pela a seção de periódicos, tem um pequeno hall, que abre para o acervo fechado/ hemeroteca e a administração, a área de apoio tem acesso tanto pela administração quanto pela seção periódicos.

A única sinalização de que existe uma biblioteca naquele local é uma placa no corredor chegando à recepção. As estantes do acervo aberto ficam todo o material mais procurado pelos usuários e mais recentes, esse acervos disponíveis são leitura local ou empréstimo pra para qualquer pessoa. E entre as estantes tem mesas para leitura em grupo, e alguns pufes distribuídos próximo as paredes para leitura individual. As estantes em sua maioria são altas algumas passando de 2 metros, onde o alcance manual dos cadeirantes mostrado nas normas acima é de $1,2 \mathrm{~m}$.

Um aspecto relevante para o novo projeto em outra área é espaços adequados e específicos para leitura, no qual podem ser utilizado pelos mais diversos público de forma individual ou coletiva. Pois os ambientes oferecidos hoje pela biblioteca necessitam dessa estrutura adequada para cada atividade a ser realizada, um lugar o qual os usuários sejam atraídos e permaneçam por estarem confortável no local.

No fundo do acervo aberto foram feitas uma estrutura improvisada para duas salas, uma delas a sala de estudo podendo ser coletivo ou individual, mas possui apenas duas prateleiras com acervos, e uma mesa redonda com três cadeiras coloridas. A outra sala é com o acervo em braile, sem nenhuma acessibilidade física, e um espaço que foi projetado para atender a necessidade do usuário.

A sala infantil fica em um local separado da biblioteca tradicional, no mesmo salão que vai pra biblioteca, as cadeiras e pufes são dispostos a atividade a ser realizadas com as crianças, que vem de escolas para desfrutar do lugar, mas quando esse evento acontece o restante do acervo fica impossibilitado de receber usuários, durante a atividade, devido a falta de espaço e lugar apropriado para devida atividade. 


\section{DISCUSSÃO}

A biblioteca atual não consegue atender a necessidade de permanência e interação entre os ambientes internos, analisando os estudos do terreno, da área de implantação e outros levantamentos, é muito importante trabalhar a funcionalidade da nova biblioteca, sua integração, trabalhando um programa de necessidades que atendam as áreas importantes para uma biblioteca ideal.

O programa arquitetônico básico são áreas de estudo, acervo, área administrativas, áreas de serviços, atendimento ao usuário e espaços para circulação e leitura. O programa pra a nova biblioteca vem enfatizar as áreas de lazer e importância da acessibilidade para pessoas com mobilidade reduzida. O conforto térmico e acústico dentro do edifício também se incluem na proposta.

A leitura pode começar em uma praça pública, e uma cafeteria que se estende até a calçada, se da a criação de uma biblioteca externa ativa e acolhedora, essencial para o bem estar da biblioteca em seu conjunto.

Uma biblioteca com ruas e calçadas animadas é chave para atrair mais visitantes e pedestres, inicia da relação entre a biblioteca pública com o espaço público, o calçadão e a área central, resgatando a importância histórica daquele lugar para a população, e inserindo o novo modelo de biblioteca, um ambiente de permanência, naquele lugar de grande circulação de cidadãos.

Um espaço que seja convidativo para as pessoas entrar, usar e permanecer fazendo a integração entre o espaço público, a praça e o calçadão, com a biblioteca, a proposta constitui em construir uma biblioteca no centro da cidade, para buscar as lembranças das noites do passado, e trazer para a área central o estimulo a leitura onde tem grande fluxo de cidadãos de baixa renda.

$\mathrm{Na}$ área construtiva, a planta será livre, com poucas paredes internas e ambientes integrados, usando o mobiliário para a separação de espaços como foi utilizado na Biblioteca OBA e de São Paulo, são elementos como os nichos usados de layout que divide os espaços internos, tornando uma edificação em constante mudança com o mobiliário.

Materiais construtivos vão ter características da Biblioteca São Paulo trazer a transparência para dentro do edifício e tornar visível o interior da biblioteca. O vidro junto com estrutura metálica, as estantes de livros ficam principalmente nas paredes, que são de concreto armado maciço para suportar a carga dos livros, e a área central fica um vão livre para a entrada de iluminação e ventilação, e ao redor o fluxo livre.

\section{CONCLUSÃO}

Conclui-se que mudando de localização a biblioteca, de um lugar mais distante para um local de mais circulação de pessoas e priorizando as características atrativas, com memorias do antigo edifício, um lugar que faz aproximação com a leitura faz com que as pessoas passem a ir a biblioteca com mais frequência ou até mesmo aqueles que não frequentavam tornam usuários desse acervo.

A biblioteca atual não consegue atender a necessidade de permanência e interação entre os ambientes internos. O programa pra a nova biblioteca vem enfatizar as áreas de lazer e importância da acessibilidade para pessoas com mobilidade reduzida.

O projeto se inicia da relação entre a biblioteca publica com o espaço público, o calçadão e a área central, resgatando a importância histórica daquele lugar para a população, e inserindo o novo modelo de biblioteca, um ambiente de permanência, naquele lugar de grande circulação de cidadãos. Trazer para a área central o estimulo a leitura, um espaço que seja convidativo para as pessoas entrar e permanecer. 


\section{REFERÊNCIAS}

DE PAULA, Ricardo. Formação Socioespacial. Histórico do Município: Imagens e recortes da história de presidente prudente. 2017 Disponível em < http://portaldoprofessor.fct.unesp.br:9000/topico/formacao-socioespacial/ > Acesso em 05 mar. 2018.

JUSTEL, Tatiana. Centro Cultural Matarazzo. 2018. Disponível em < http://estadodacultura.sp.gov.br/espaco/199/\#tab=sobre> Acesso em 25 mar. 2018.

PORTAL PRUDENTE. História de Presidente Prudente SP. Disponível em < http://www.portalprudente.com.br/prudente.htm > Acesso em 05 mar. 2018.

PORTAL PRUDENTE. História de Presidente Prudente SP. Disponível em < http://www.portalprudente.com.br/prudente.htm > Acesso em 05 mar. 2018.

PRESIDENTE PRUDENTE. Secretaria Municipal de Cultura: Biblioteca. 2014. Disponivel em : http://www.culturapp.com.br/index.php/equipamento/biblioteca/> Acesso em 17 mar. 2018.

SCHWAMBACH, K. F.; ASSAD, C. C.; LANZETTA, G. B. III Seminario internacional urbicentros Salvador: UFBA. Revivendo os alto-falantes como elemento de memória coletiva do centro histórico de Presidente Prudente-SP. 2012. Disponivel em < http://www.ppgau.ufba.br/urbicentros/2012/ST155.pdf> Acesso em 17 mar 2018. 